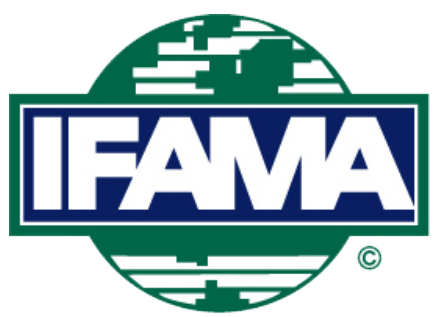

International Food and Agribusiness Management Review

Volume 23, Issue 4, 2020; DOI: 10.22434/IFAMR2019.0130

Received 13 August 2019 / Accepted: 25 June 2020

\title{
EastPack: financing future growth opportunities
}

'Growers at heart, future in mind'

EastPack (2017)

\section{CASE STUDY}

\author{
Elena Garnevska ${ }^{\circledR a}$, Farai Sixpence ${ }^{\mathrm{b}}$ and Whetu Rolleston ${ }^{\mathrm{b}}$ \\ ${ }^{a}$ Senior Lecturer, ${ }^{b}$ Graduate student, Massey University, School of Agriculture and \\ Environment, Private bag 11222, Palmerston North, Manawatu 4410, New Zealand
}

\begin{abstract}
EastPack was a New Zealand cooperative providing post-harvest services for its kiwifruit and avocado growers. EastPack was New Zealand's largest kiwifruit postharvest company with a packing capacity of more than 40 million trays ${ }^{1}$ of kiwifruit. It was forecasted that New Zealand kiwifruit volumes would increase by about $50 \%$ by 2025 . While this was great news for the growers and Zespri - the marketer, it presented a challenge to post-harvest operators like EastPack since they would need to increase their capacity in order to cope with this growth. EastPack needed to develop strategies to manage the strong kiwifruit growth prospects, fund capacity expansion and ensure its growers remained at the heart of their growth.
\end{abstract}

Keywords: growth strategies, New Zealand, kiwifruit, EastPack, New Zealand horticulture, food and agribusiness industry JEL code: Q13, D70, O56, L11

(1) Corresponding author: e.v.garnevska@massey.ac.nz

${ }^{1}$ One tray represents one export grade carton of kiwifruit of $3.6 \mathrm{~kg}$ net weight and is a standardised unit of measure. 


\section{Introduction}

Hamish Simson, CEO of EastPack Ltd (New Zealand's largest post-harvest company) sat at his desk and thought about the growth of the New Zealand (NZ) kiwifruit industry. The industry was recovering from the outbreak of the Pseudomonas syringae pv.Actinidiae (PSA) disease ${ }^{2}$ and the industry was expecting to grow over the coming years. The impetus for this growth came primarily from the new Gold kiwifruit variety, SunGold (G3). In 2017, Zespri ${ }^{3}$ made clear its intent to grow sales revenue from NZ\$2.1 billion to NZ\$ 4.5 billion by 2025. It meant that New Zealand volumes would increase from about 123 million trays to 190 million trays. Simson reflected: 'the challenge with our core business is the amount of growth, how is EastPack going to be able to pack the increased kiwifruit volume? Our core business is capital hungry'.

EastPack had a long and proud history of being at the forefront of innovation and efficiencies in both its operations and cooperative structure. Attention to continuously improving productivity while simultaneously lowering growers costs had enabled the company to grow organically while, at the same time a strong balance sheet allowed EastPack to take advantage and grow through strategic mergers and acquisitions.

Simson thought about the future opportunities and threats for EastPack and the New Zealand kiwifruit industry. Now, the challenge for the company was to ensure sufficient capacity to handle the growth in kiwifruit volumes. However, he was also cautious about the potential danger of another disease outbreak or pest incursion that could affect kiwifruit production at any time. For the past three years, EastPack had increased its debt to fund capacity expansion projects to cater to its grower shareholders. As a cooperative EastPack was also capital constrained. EastPack was still dealing with the effects of the PSA-fueled downturn that lead to a period of reduced revenues and profits. But the new growth outlook called for investment not only in new pack house and cool storage facilities, but also in the various support systems and people to run the enlarged company. EastPack's growth could not continue to be funded purely out of debt. Simson's biggest question was how to capture growth from a growing industry? How could the cooperative continue to provide the services demanded by its growers? Was a cooperative structure the best business model for them?

\section{Global kiwifruit market}

\subsection{Global kiwifruit production}

The global kiwifruit category was a relatively recent entrant in global fruit trade and accounted for just over $0.2 \%$ of all fruits in the global fruit bowl. In 2017, global kiwifruit production was estimated at 6 million tons, valued at NZ\$2.66 billion. The top five producers were China followed by Italy, New Zealand, Iran, and Greece and together accounted for $58.7 \%$ of global output (Supplementary Exhibit 1). After a decade of rapid growth in output during the 1980s, the 1990s was characterized by stabilized production at around 900 million tons. Since 2000, global production had again entered a new growth phase with global output increasing from 1.87 million tons to 3.26 million tons in 2013 . The recent growth phase was driven almost exclusively by a significant increase of production in China. Between 2000 and 2013, China's output had grown from 850,000 tons to over 1.7 million tons and grew from 45 to $54 \%$ of the total world volumes (Supplementary Exhibit 2). In contrast, other major producers remained relatively stable in output, while New Zealand production was estimated to grow from about 150,000 MT to over 350,000 MT (Figure 1).

\footnotetext{
${ }_{2}^{2}$ Pseudomonas syringae pv.Actinidiae is a kiwifruit-specific pathogenic bacteria that can undermine plant health and cause plant death.

${ }^{3}$ Zespri is a sole exporter of New Zealand Kiwifruit outside of New Zealand and Australia.
} 


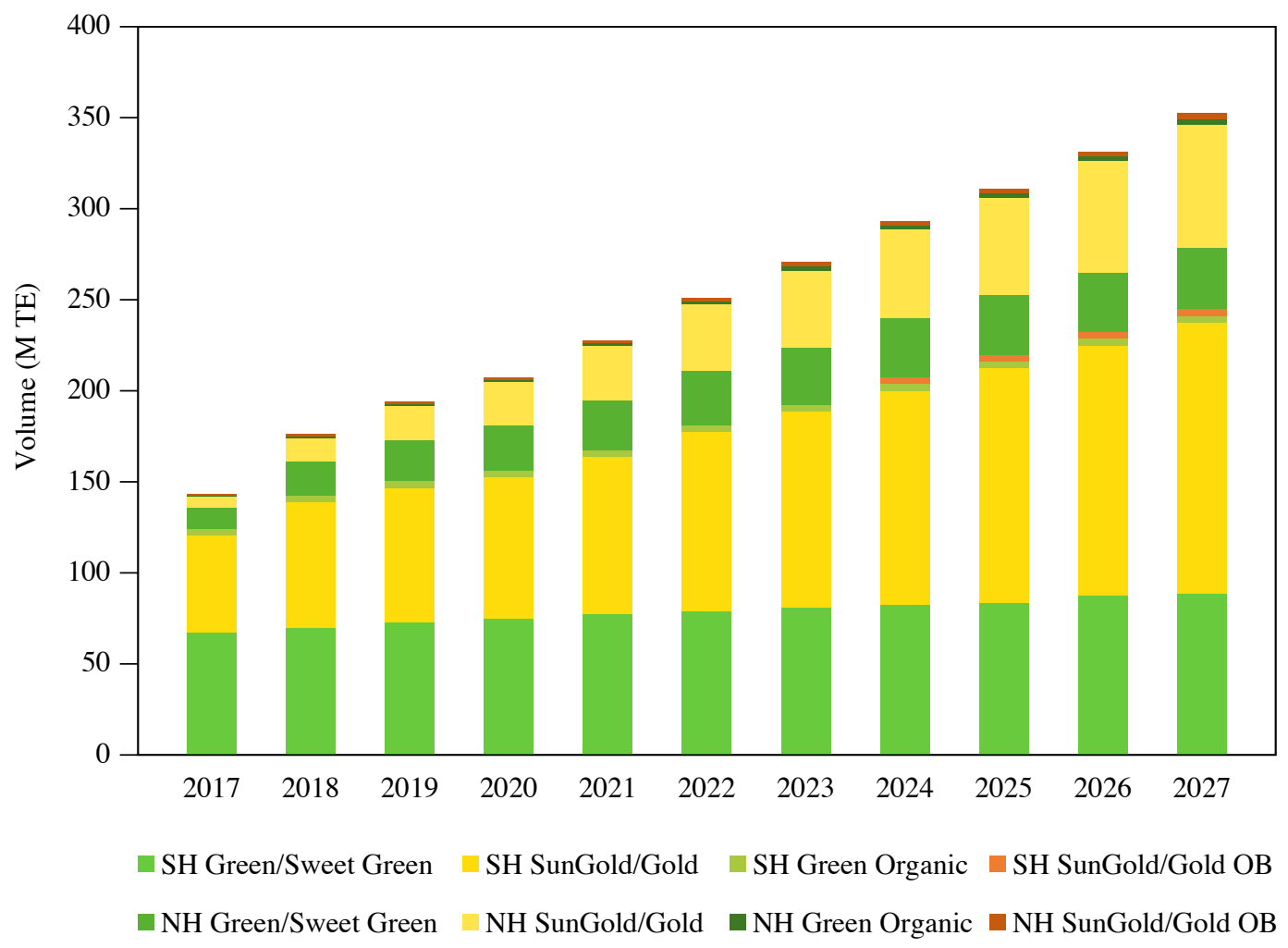

Figure 1. Zespri’s 10 year demand outlook 2017-2027 (Zespri, 2018).

\subsection{Global kiwifruit trade}

Global kiwifruit exports in 2017 totaled 1.05 million tons valued at US $\$ 2.05$ billion. The top five exporting countries were New Zealand followed by Italy, Chile, China, and Lithuania and together accounted for $94 \%$ of world exports worth US\$2.04 billion (Supplementary Exhibit 3). New Zealand and Italy accounted for over $74 \%$ of all kiwifruit exports. The top five exporting countries remained dominant in world trade since the 1990s. Within the next 10 years however, China was expected to become a major player in the export trade and shift from a net importer, to a net exporter of kiwifruit. In 2017, the top five importing countries were Spain, Germany, Japan, Russia and Italy and together accounted for $62 \%$ of all imports (Supplementary Exhibit 4).

\section{New Zealand kiwifruit industry}

Kiwifruit was New Zealand's largest single horticultural export by volume and value in 2017, representing $38 \%$ of the total horticulture export revenue (Table 1). New Zealand exported $30 \%$ of the world's exported kiwifruit valued at NZ\$ 1.66 billion $^{4}$. The top markets for NZ kiwifruit were China, Japan and EU (Spain, Germany, Benelux) (Supplementary Exhibit 5).

The New Zealand kiwifruit industry included approximately 2,500 growers controlling over 12,000 hectares in kiwifruit production, 15 post-harvest companies (EastPack, Seeka and other 13 smaller postharvest companies), and Zespri Group Ltd, a sole exporter of New Zealand Kiwifruit outside of New Zealand and Australia (Supplementary Exhibit 6 about details on NZ kiwifruit industry structure). Zespri was 100\% owned and controlled by past and current New Zealand kiwifruit growers and aimed to maximize returns for all New Zealand kiwifruit growers. Zespri is required by law to be registered as an NZ limited liability company yet

\footnotetext{
${ }^{4} \mathrm{NZ} \$ 1=\mathrm{US} \$ 0.60$.
} 
Table 1. Horticulture export revenue 2015-2021 (NZ\$ million) (MPI, 2018; Stats NZ, 2018).

\begin{tabular}{lrrrrrrr}
\hline Year to 30 June & $\mathbf{2 0 1 5}$ & $\mathbf{2 0 1 6}$ & $\mathbf{2 0 1 7}$ & $\mathbf{2 0 1 8}$ & $\mathbf{2 0 1 9}$ & $\mathbf{2 0 2 0}$ & $\mathbf{2 0 2 1}$ \\
\hline Kiwifruit & 1,182 & 1,673 & 1,664 & 1,861 & 2,302 & 2,480 & 2,690 \\
Wine & 1,408 & 1,558 & 1,661 & 1,694 & 1,807 & 1,830 & 1,830 \\
Apples and pears $^{\text {Fresh and processed vegetables }}{ }^{1}$ & 571 & 701 & 701 & 745 & 839 & 870 & 920 \\
Other horticulture $^{2}$ & 588 & 612 & 614 & 622 & 696 & 660 & 670 \\
Total $^{\text {Tol }}$ & 436 & 456 & 525 & 471 & 466 & 450 & 530 \\
\end{tabular}

${ }^{1}$ Fresh vegetable exports include onions, squash, capsicum, potatoes and other fresh vegetables. Processed vegetable exports include frozen vegetables (including frozen potatoes, peas, sweetcorn, etc.), dried vegetables, dry legumes, prepared and/or preserved vegetables, and vegetable juices.

${ }^{2}$ Other horticulture exports include: other fresh fruit (including avocados, cherries, blueberries, etc.), frozen and processed fruit, fruit juices, nuts and ornamentals.

it did share much in common with cooperatives. The Bay of Plenty region accounted for approximately $80 \%$ of kiwifruit production. The picking and packing season for New Zealand kiwifruit was between middle of March to end of June. Green kiwifruit (Hayward) was traditionally produced and exported, however, since 2000 the new Gold variety kiwifruit (Hort 16A) was introduced and very successful but replaced by SunGold G3 variety after the PSA disease. The price premium for Gold kiwifruit was about 50\% higher compared to the traditional green kiwifruit (Supplementary Exhibit 7).

The development of new kiwifruit varieties contributed to the success of the New Zealand kiwifruit industry however, research and development into new varieties was also ramping up in other countries and particularly in China. Zespri had a number of newly developed varieties under trial. The SunGold G3 variety was under pre-commercial trials for some time when PSA struck. In 2013, Zespri released the Gold G3 variety as a replacement option for Gold Hort16A. The cultivar proved to be more resistant to PSA, was much easier to grow and could produce much higher yields. In the markets it commanded a higher price and was in high demand by consumers. More than 4,300 hectares of the G3 variety was licensed in New Zealand with more than 60 million trays being marketed as Zespri SunGold Kiwifruit. In 2017, Zespri revised the industry growth plan and announced its intention to release 700 hectares each year of G3 license to New Zealand growers from 2017 to 2022 . The industry had almost recovered the volume-loss due to PSA, but Zespri's announcement placed new future capacity pressures on post-harvest operators.

The kiwifruit industry was susceptible to prevailing global and national economic conditions as well as unforeseeable events that could affect the New Zealand's horticulture industry. One notable event was the outbreak of the PSA that in fact proved too virulent for the gold kiwifruit variety, Hort 16A. The PSA disease was discovered in 2010 and exponentially spread to $80 \%$ of New Zealand Gold kiwifruit orchards. The greatest impact was seen in the 2013/14 season when grower payments went down by $17 \%$ due to a $55 \%$ reduction in volumes of Gold kiwifruit.

New Zealand's closest global competitor was Chile since southern hemisphere producers competed directly for shelf space in tropical and northern hemisphere markets. New Zealand growers had a relatively higher cost of production in comparison to Chile (Supplementary Exhibit 8). For these reasons in the early 2000's, Zespri set out on a branding and differentiation strategy to position Zespri kiwifruit as high value products in export markets and in turn, increased returns relative to its global competitors (Supplementary Exhibit 9). Other world producers of kiwifruit attempted to capture the market using price incentives, but New Zealand focused on value addition through product taste, quality, consistency, branding, promotional support and reliable supply. 


\section{EastPack Ltd}

\subsection{Establishment and development}

EastPack formerly known as Rangaitaki Fruit Packers Limited was established in 1983 (Supplementary Exhibit 10). EastPack was a grower owned cooperative that operated a kiwifruit and avocado packing and cool storage business, managed and leased orchards, and provided on-orchard management services. The cooperative had packing facilities in Northland, the Western Bay of Plenty and Eastern Bay of Plenty. 68\% of EastPack's production was centralized across three sites in Te Puke ${ }^{5}$. EastPack Limited was parent company to EastPack Group which had six subsidiaries (Table 2).

EastPack was the largest kiwifruit post-harvest operator in New Zealand with a packing capacity of more than 40 million trays of kiwifruit and handled about $29 \%$ of New Zealand's kiwifruit production. One of the key drivers for EastPack's success was its ability to maintain and grow volumes of kiwifruit and avocados packed and cooled, stored and loaded out for sale. In 2017, EastPack packed 33.4 million trays of kiwifruit for its growers and in 2018 it was a record year and the company packed 41.1 million trays of kiwifruit. For this year, EastPack also packed 0.8 million trays on behalf of other post-harvest companies who utilized the company's Near Infra Red (NIR) ${ }^{6}$ technology capability.

EastPack's profitability was reliant on the price it could charge for the services provided. Operating in a very competitive post-harvest industry meant margins were tight and growers were at an advantage to change post-harvest companies with very little notice. Seasonal conditions could also affect budgeted predictions on volume expectations both positively or negatively with subsequent effects on annual profits. EastPack's reputation and results for its grower shareholders had supported organic growth and growers had chosen to move to EastPack for the profitability they experienced in their own orchard businesses.

EastPack had adopted a 'Grower Excellence' and LEAN manufacturing program to drive profitability and reduce waste. Through the program, in 2013 EastPack was able to reduce cost and waste by $28 \%$. The company invested substantially in its people, technology, and capacity improvements as well as making significant investment into strengthening its services to support its growers' needs. EastPack also had a

Table 2. EastPack Group subsidiaries and companies (EastPack, 2017).

\begin{tabular}{|c|c|c|}
\hline Subsidiary companies & EastPack's interest & Principal activity \\
\hline South Link Supply Ltd & $100 \%$ & $\begin{array}{l}\text { Administration services and industry representation in } \\
\text { respect of produce supplied }\end{array}$ \\
\hline EastPack Kiwifruit Operations Ltd & $100 \%$ & Involved in the management of leased orchards \\
\hline EastPack Avocado Company Ltd & $100 \%$ & An avocado supplier \\
\hline Company & EastPack's interest & Principal activity \\
\hline The Nutritious Kiwifruit Company & $50 \%$ & Sales of kiwifruit in Australia \\
\hline Kiwi Produce Ltd & $20 \%$ & Contract packer, processor and marketer of fruit \\
\hline Tauranga Kiwifruit Logistics Ltd & $34 \%$ & Manages port logistics for the export of kiwifruit \\
\hline
\end{tabular}

${ }^{5}$ Te Puke is a small town in the northern part of the north island in NZ, a major kiwifruit growing region.

${ }^{6}$ NIR enables non-destructive measurement of individual fruit for specific fruit criteria. The 2016 was considered a low dry matter year and NIR enabled eligible fruit to be recovered that under normal circumstances would have been rejected. EastPack was the only postharvest operator to have this technology. 
history of investing in, developing, trailing and adopting innovative solutions to problems such as controlled atmosphere, pre-cooling systems, Near Infra Red, and were examples of solutions that became standard in the post-harvest sector.

The merger with Satara in 2013 during the PSA downturn resulted in a period of excess capacity where EastPack concentrated most of its packing through its pre-merger sites. The growing kiwifruit industry enabled EastPack to reinvest in these latent assets over time as volumes of fruit began to match this excess capacity. In 2015, the company built more infrastructure in anticipation of increased fruit volumes and had made investments of more than NZ\$ 70 million in land, buildings, plant and machinery. But EastPack knew that the excess capacity would be short lived, and industry growth would require more infrastructure in near future.

Other investments that EastPack had made included: the NZ\$20 million investment for the development of the Te Puke processing site in 2001 and the NZ\$ 9 million investment for the development of a semiautomated fruit grader and sizer and cool stores in Te Puke in 2009. Based on the growth forecasts, EastPack decided to invest and install a second grader at Washer Road to increase cool store and pack house capacity at Opotiki, Quarry Road and Collins Lane.

\subsection{EastPack ownership}

EastPack was a grower owned cooperative with about 700 member shareholders. Ownership was limited only to New Zealand kiwifruit and avocado growers. In 1997, EastPack established two classes of shares named 'transactor' and 'investor' shares. Transactor shares required each supplying grower to provide an initial investment per quantity of fruit supplied (NZ\$ 1.00 per tray of $1^{\text {st }}$ class kiwifruit) and in return growers had the right to participate in any rebates declared by the board. In the event of company liquidation, transactor shareholders had first rights on redemption at NZ\$1.00/share. The board might at its discretion made a call on part or all of outstanding unpaid transactor shares. Historically rebates had been used as the vehicle for the recovery of any calls on outstanding shares. For instance, in 2016 the board called for the retention of NZ\$ 0.10/tray out of a total rebate value of NZ\$ 0.20. During the PSA downturn, in 2012 the board declared no call on shares would be issued due to the financial pressures its growers were facing. Such policies had helped EastPack's organic growth during the 2000s' as upfront shareholder capital was not required. Any transactor shareholder who retired or ceased to supply fruit to EastPack could trade shares with other transactor shareholders, or might surrender shares back to EastPack (with payment deferred for 3-5 years). Transactor shareholders carried $60 \%$ of the voting rights and were entitled to one vote for every NZ\$ 1.00 paid up registered shares. Transactor shareholders were entitled to any rebates declared by the board (considered after EBITDA pre-profit) and were committed to a minimum of NZ\$ 0.20/tray packed. The maximum rebate payable to transactor shareholders in a year was NZ\$ 0.30/tray.

Only transactor shareholders could hold investor shares. The cap established by the board was 4 investor shares to 1 transactor share. Initially, Investor shares were allocated to the original shareholders. Investor shares had the right to participate in any dividends declared by the board with a distribution policy dependent firstly on having an ability to pay a minimum threshold value of NZ $\$ 0.20$ /tray to its transactor shareholders. EastPack had about 24 million Investor shares on issue. They were tradable between EastPack shareholders at market value via the sharemart platform (Supplementary Exhibit 11) and hold no par value. Investor shares carried $40 \%$ of the voting power and were entitled to receive annual dividends declared by the board. In 2016 after a profitable year, transactor shareholders were paid NZ\$ $0.27 /$ share rebate, and investor shareholders received dividends of NZ\$ 0.12/share. Conversely in 2014 on lower profitability, the board paid out NZ\$ 0.20 /tray rebates and NZ\$ 0.03/investor share (Figure 2).

EastPack was governed by a board of directors consisting of eight elected grower directors and two independent commercial directors. The chairman of the board was selected from one of the eight elected grower directors. The board of directors was responsible for making key strategic decisions including selecting and appointing the CEO. Maximum tenure for a shareholder director was 12 years. 


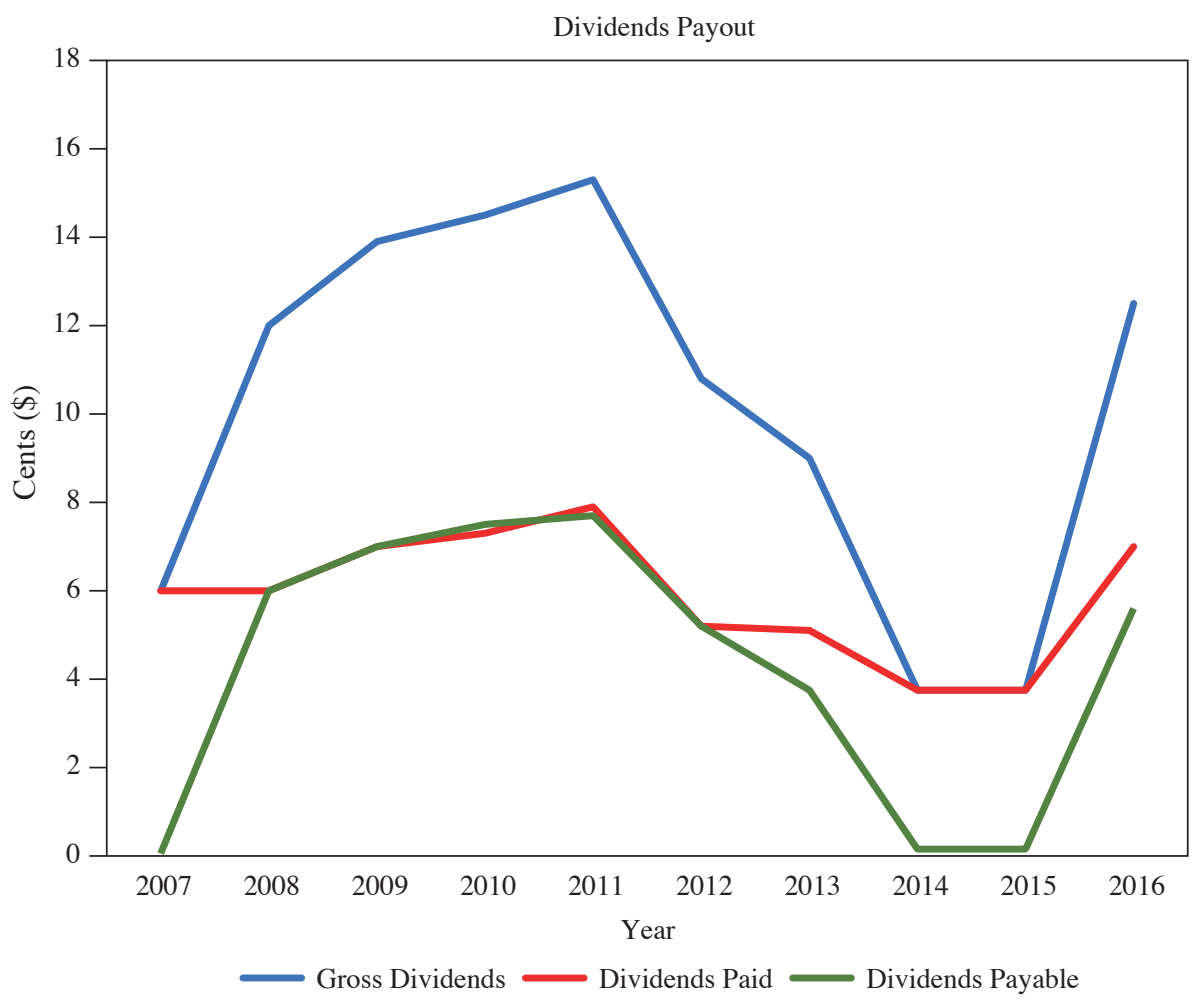

Figure 2. EastPack dividend paid trend (EastPack, 2017).

\subsection{Merger and strategic alliances}

'No transition is ever smooth especially when joining two companies that have different cultures'

- Hamish Simson, CEO of EastPack

In 2013, EastPack merged with Satara, making the cooperative the biggest merger in the New Zealand's kiwifruit industry. The merger happened during a time in which the kiwifruit industry experienced a reduction in fruit volumes due to the PSA incursion which resulted in both companies operating at a loss due to the reduction in kiwifruit volumes.

The PSA outbreak resulted in a drop in kiwifruit volumes to about 24 million trays which then led to the newly formed company owning excess production capacity. Both entities had infrastructure and capacity to accommodate more than 24 million trays and the merger brought EastPack new prospects for improved capability to handle production increases. It also assisted EastPack to be able to maintain orchard gate returns and returns from the high volumes of throughput.

EastPack also joined forces with another three businesses (OPAC, DMS and Trevelyan's) and formed a company for marketing Class 2 kiwifruits to Australia. This joint venture developed the Nutrikiwi brand for the Australian market. This allowed the companies to benefit from economies of scale, which would have been difficult to achieve if done separately. The strategic alliance was also beneficial to the member shareholders as they received a higher return for their class 2 kiwifruit that accounted for about $5 \%$ of their fruit crop. 


\subsection{EastPack competitors}

In 2017, there were about 50 packing facilities and 73 cool stores used in the kiwifruit industry. The top five post-harvest operators in New Zealand were: EastPack; Seeka; Apata Group; DMS Progrowers; and Trevelyan's Pack and Cool. Together EastPack and Seeka held over 50\% of market share by volume while the remaining three each controlled about $10 \%$.

Competing for market share was intense in the late 2000s' and again during the period of PSA industry downturn due to lowered volumes. EastPack's nearest competitor Seeka, a publicly owned company experienced similar market share and looked also to capture opportunities during industry disruption. The merger of EastPack and Satara brought new prospects for improved capability to handle production increases but Seeka also grew through acquisitions and mergers and kept pace with its nearest competitor EastPack.

The number of post-harvest companies declined over the last ten years as strategic mergers and acquisitions lead to consolidation within the sector while high capital investment presented barriers to new entrants. Zespri's growth plans appeared to diffuse what was an intense period of post-harvest competition and companies now turned inward to ensure they could firstly meet their existing grower's needs as they themselves grew. But balance sheets were stretched and debt levels were again on the rise.

Seeka $^{7}$ was EastPack's major competitor and was the second largest kiwifruit packer with similar market share. It was a Te Puke-based publicly listed company with operation in Australia and New Zealand. Seeka's New Zealand operations provided services that range from growing, picking, processing and dispatching kiwifruit, avocados and kiwiberry. The company was also a major importer of bananas and other tropical fruits to New Zealand. Through the purchase of Kiwi Crush, the company expanded its services to food processing to provide increased returns to growers and stakeholders. About 58\% Seeka's revenue was derived from its kiwifruit post-harvest operations. In 2016, Seeka handled about 32.44 million trays of New Zealand kiwifruit (Supplementary Exhibit 12 for more details on Seeka financial performance). Just like EastPack, Seeka made significant investments in their post-harvest operations to increase capacity and processing capabilities. In 2017, in addition to developing a NZ\$ 16.4 million kiwifruit cool store and packing infrastructure the company also invested in packing machine, a new Compact Spectrim.

\section{EastPack: future outlook}

'The reality for us is that we are very much a service company to the needs of the fruit.

If the growers are growing more fruit they need to pick it when it's ready, they don't have

a lot of wriggle room in terms when they pick the fruit. When it's ready it's ready'

- Hamish Simson, CEO of EastPack

EastPack packing capacity was reaching its limits to capture the forecast kiwifruit production growth. The installation of the new grader, the extension of the pack house building and the construction of a cool store at Washer Road resulted in a significant increase of EastPack capacity handling capabilities. When growers picked their kiwifruit, EastPack needed the capacity to handle the fruit. If EastPack did not have the capacity, growers could face significant loss through inadequate storage facilities. As a cooperative, the growers/ members would expect that their organisation would serve their needs and when they anticipated increasing fruit volumes EastPack would have strategies to increase their packing capacity.

EastPack would continue investing and upgrading existing plants to provide the best cooling and storage of fruit and would invest in new technology to support efficiency gains in its operations. The estimated cost of a new site was about NZ\$ 70 million. Projects undertaken by EastPack so far had mainly focused on expansion of existing plants. An increase of 50\% volume will require innovative solutions.

\footnotetext{
${ }^{7}$ https://tinyurl.com/y53ee2se
} 
'Every extra tray we pack needs extra capital'

- Hamish Simson, CEO of EastPack

EastPack had steadily increased debt over the past few years to ensure they had adequate capacity to handle the steady increase in fruit volumes (Supplementary Exhibit 13 for more details about financial performance). The capital needed to build additional infrastructure would exceed NZ\$100 million. As a cooperative, EastPack could not continue to fund the growth purely out of debt because the payback on any capital investment would require long term debt. The growth that the kiwifruit industry was experiencing was too fast for investments to be repaid before new investments were required.

The leadership at EastPack was not so concerned about increasing market share, because the industry as whole was growing and priority was put on making sure that the company had the capacity to cope with the growth.

'The company will be growing strongly because the whole industry is growing'

- Hamish Simson, CEO of EastPack

Considering the current capital constraint, what strategies would you recommend to ensure that EastPack's capacity would increase in order to be able to capture the growth of the NZ kiwifruit sector? What factors (e.g. production/efficiency, risk, financial, marketing, legal) would you consider when discussing the ability of the existing cooperative business model to address the challenges and opportunities presented by the growing market? Was restructure of their cooperative business model necessary in near future?

\section{Supplementary material}

Supplementary material can be found online at: https://doi.org/10.22434/IFAMR2019.0130

Exhibit 1. Top five kiwifruit producing countries by share of global production 2017.

Exhibit 2. Historic production of the top five kiwifruit producing countries 2000-2017.

Exhibit 3. Top ten kiwifruit exporting countries 2017.

Exhibit 4. Top ten importing kiwifruit countries 2017.

Exhibit 5. Top 10 markets for Zespri kiwifruit.

Exhibit 6. The New Zealand kiwifruit industry structure.

Exhibit 7. New Zealand average orchard gate returns 2007-2017.

Exhibit 8. Hayward (Green kiwifruit) Chile vs NZ cost of production 2004-2013.

Exhibit 9. New Zealand vs Chilean returns in US\$ per kilo 2009-2013.

Exhibit 10. EastPack group history.

Exhibit 11. Sharemart platform.

Exhibit 12. Seeka post-harvest performance.

Exhibit 13. EastPack financial performance 2017.

Teaching Note.

\section{References}

Eastpack. 2017. EastPack annual report 2017 and 2018. Available at: https://www.eastpack.co.nz/financiallegal-info

Ministry for Primary Industries (MPI), 2018. Situation and outlook for primary industries (SOPI) reports. MPI, Wellington, New Zealand. Available at: https://tinyurl.com/yyubxdyo

Statistics New Zealand, 2018. Statistics NZ. Wellington, New Zealand. Available at: https://www.stats.govt.nz/

Zespri. 2018. The New Zealand kiwifruit industry future opportunities and challenges. Zespri, Mount Maunganui, New Zealand. Available at: https:/tinyurl.com/y9zmg393 
